\title{
The Effects of Horticultural Activity with Reminiscence Materials and Singing Time on the Ability to Recall Words and Depression in the Elderly with Mild Dementia
}

\author{
Jung Min Kim', Suk Young Yun ${ }^{2 *}$, Byung Jin $\mathrm{Choi}^{2}$, and Mun Su Cho ${ }^{3}$ \\ ${ }^{1}$ Daegu Metropolitan City Seobu Genatric Hoapital, Daegu 41845, Korea \\ ${ }^{2}$ Department of Horticulture, Daegu Catholic University, Gyeongsan 38430, Korea \\ ${ }^{3}$ Department of Horticulture, Daegu University, Gyeongsan 38430, Korea
}

\begin{abstract}
The purpose of this study was to investigate the effects of horticultural activities with reminiscence materials and singing songs on the ability to recall words and depression in the elderly with mild dementia. A total of 20 sessions of a horticultural therapy program was held once or twice a week from July 14, 2015 to November 3, 2015 for the elderly with mind dementia at the social welfare center in $D$ city. The subjects of this study were 13 women and the mean age was 81.2 years. The ability to recall words significantly improved from $8.6 \pm 1.8$ before the program to $9.4 \pm 0.6$ after the program $(p=.012)$. However, there was no significant difference in the score of depression after the program. Synergistic effects were generated by applying horticultural activities, singing and reminiscence therapy activities simultaneously, and it was effective in recalling memories. As emotional functions were associated with hormones in vivo, there were emotional ups and downs at each session and short-term alternative therapies were not sufficient to completely eliminate neurotoxic substances caused by dementia.
\end{abstract}

Keywords: alternative therapy, synergistic effect, welfare center

\section{Introduction}

Dementia is a brain disease that causes memory disorder and at least one cognitive functional disorder among various cognitive functions of the frontal lobes including memory, attention, linguistic ability, visuospatial ability and judgment, resulting in difficulties in daily life and social life. Senile dementia is caused by degenerative changes in the brain due to aging, and the disease slowly progresses over time (Jung, 2008). These cognitive functional disorders increase the prevalence rate of depression (Bullock and Hammond, 2003), and decrease communication skills and spontaneous behaviors, which frequently causes depressive symptoms (Keightley and Mitchell, 2004).

Recollection is not just an simple act of remembering an incident, but it is also very important to recall situations related to the incident and thus to feel the emotions that were felt back then, which is in particular useful to patients with dementia. Recollection is a way to provide an exit from strong emotional expressions, unsolved problems, suppressed feelings, etc. 
and an opportunity to recall the memory of the past (Hamacheck, 1990). It is also important for the elderly to recall old memories (Butler, 1963).

Horticultural activities are helpful for the elderly to bring back old memories and have positive emotions (Heo and Park, 2010). Although they are slow, they can continuously learn the names of plants and horticultural activities, and the activities activate the left and right brains through the sensitivity and images that plants give and restore the memory and sensitivity of the elderly (Han, 2010). That is, a variety of horticultural activities including cultivating plants and decorating flowers promote physical and mental recovery and rehabilitation and improve the overall quality of life (H.Y. Kim, 2003).

Music therapy among various programs for the elderly has been recognized as an effective therapy for senile diseases such as dementia and stroke (Aldrige, 1994), and it is also helpful for other purposes such as training sensory organs, perception of reality, motivation, entertainment and pastime activities and recollection. Singing provides an opportunity to express pain, fear and anger, to share pleasure and to show the reality of daily life. Music therapy also allows to approach the spiritual and mental part of life, and to bind a community through interactions with others (Jung, 2006).

As discussed above, recollection, horticultural activities and singing have a positive impact on the cognitive ability and emotions of the elderly, and thus this study aimed to examine the effects of horticultural activities that incorporate singing and recallable horticultural materials on the word-recall ability and depression of the elderly with mild dementia, among their cognitive and emotional functions.

\section{Research Methods}

\section{Subjects}

This study was conducted on senior citizens with mild dementia (MMSE 24 30 points) who used services provided by A social welfare center located in D city. There were 20 persons who showed their intention to participate in activities and signed a consent form, but 13 persons who did not miss any session and participated in assessment were selected as the final subjects of this study. Their average age was 81.2 years and all of them were female.

\section{Tools}

\section{Program design}

In this study, a program for the elderly with mild dementia who used the welfare center to participate in horticultural and singing activities together using horticultural materials that induce the recollection of memories was designed as shown in Table 1 in order to examine the effects of these activities on cognitive and emotional functions.

Horticultural activities using materials that can induce recollection provide an opportunity for the elderly to talk about their experience in the past and stimulate their memory (Kong et al., 2015) and to promote a sense of closeness in the process of living together with and feeling nature, and cultivating plants (Davis, 1994). The horticultural activity program also has a positive impact on the reduction of the depression of senior citizens with dementia (Kim and Park, 2015). To induce recollection, the program used in this study was composed of horticultural activities using materials that the subjects might experience in the past such as impatiens balsamina, Chrysanthemums, Berchemia berchemiaefolia fruits, straw hats and acorn to ensure the subjects talk about their memories with others during the activities.

Music improves the quality of life of the elderly with dementia (Clair and Bernstein, 1990), is effective in improving recollection, sociality and positive emotions (Lord and Garner, 1993), and stimulates the memory of patients with dementia with lyrics and melodies (Prickett and Moore, 1991). Using patients' favorite music is the most effective way to treat them 
Table 1. Horticultural activity program and list of songs performed for this study

\begin{tabular}{|c|c|c|c|c|}
\hline No. & Date & Horticultural activity & Reminiscence material & Song title \\
\hline 1 & Jul. 14 & Create a scent bag & Poppy, linen bag & What's wrong with my age \\
\hline 2 & Jul. 21 & Heart-shaped flower arrangements & $\begin{array}{l}\text { Callistephus chinensis } \\
\text { Chamaecyparis obtusa }\end{array}$ & What's wrong with my age \\
\hline 3 & Jul. 28 & Decorate fans using pressed flowers & Korean paper, fan & What's wrong with my age \\
\hline 4 & Aug. 04 & Water cultivation & Dracaena sanderiana & Island village teacher \\
\hline 5 & Aug. 18 & Create a wreath & Straw hat & Island village teacher \\
\hline 6 & Aug. 25 & Making a topiary using flowers & Chrysanthemum morifolium & Island village teacher \\
\hline 7 & Sep. 01 & Making pots using napkins & Cosmos painting & Like the stars in my heart \\
\hline 8 & Sep. 08 & Transplanting plants to pots & Chlorophytum comosum & Like the stars in my heart \\
\hline 9 & Sep. 10 & Create mist & $\begin{array}{l}\text { Impatiens balsamina } \\
\text { Mirabilis jalapa }\end{array}$ & Like the stars in my heart \\
\hline 10 & Sep. 15 & Directing nature in glass & Valley, Soil pots & I can't live without you \\
\hline 11 & Sep. 22 & Make wall hangings & Herbal medicine material & I can't live without you \\
\hline 12 & Sep. 24 & Flower arrangements & Colored paper, Hanbok & I can't live without you \\
\hline 13 & Oct. 06 & Decorating mini-instruments & Four-leaf clover & A road lined with cosmos \\
\hline 14 & Oct. 08 & Making attractive topiary & Hedera helix & A road lined with cosmos \\
\hline 15 & Oct. 13 & Make a bouquet & Berchemia berchemiaefolia & A road lined with cosmos \\
\hline 16 & Oct. 15 & Transplanting plants to pots & Chrysanthemum morifolium & A broken wall clock \\
\hline 17 & Oct. 20 & Making a washboard instrument & Acorn & A broken wall clock \\
\hline 18 & Oct. 22 & Orchid planting & Neofinettia falcata & A broken wall clock \\
\hline 19 & Oct. 27 & Soap making, flower stamp & Rosa multiflora & Wild rose \\
\hline 20 & Nov. 03 & Flower arrangements for memorial day & Rice cake & Wild rose \\
\hline
\end{tabular}

(Radocy and Boyle, 1988). When collecting the consent form of the subjects, their favorite songs were also surveyed and recorded, and <내 나이가 어때서 (What's wrong with my age)> was found to be the most favorite song, followed by <섬 마을 선생님 (Island village teacher)>, <내 마음 별과 같이 (Like the stars in my heart)>, <그대 없이는 못살아 (I can't live without you)>, 〈코스모스 피어있는 길 (A road lined with cosmos)>, <고장난 벽시계 (A broken wall clock)> and <찔레꽃 (Wild rose)>. These seven songs were selected and the subjects song each song together for three sessions repeatedly after participating in horticultural activities.

\section{Program execution}

In the program, a total of 20 sessions were provided from July 14 to November 3, 2015, and were led by a Grade 1 welfare horticultural therapist (certified by the Korean Horticultural Therapy Association) and assisted by a nurse and a social worker. While participating in horticultural activities using horticultural materials that induce recollection, the subjects were instructed to repeatedly say the date and day of each session, and the name of materials used in each session, to talk about their experience related to the materials and to count and say the color of the materials in order to improve their cognitive function. Finished samples were shown to the subject to increase their interest and enjoy activities, and the subjects helped each other when distributing materials and performing each step. After completing all the activities, they talked about what they intended to express with their work and encouraged each other to give a sense of confidence and satisfaction and to positively affect their emotions. 


\section{Assessment tools}

\section{Word-recall ability}

Word-recall cards designed to assess the immediate word-recall ability of examiners in the Alzheimer's Disease Assessment Scale-Cognitive subscale (ADAS-Cog-K) (KAGP, 2003) were used to measure the ability before and after performing the program. Ten words printed on white cards were presented to the subjects, and they were instructed to read aloud, and to recall the words twice. Their immediate word-recall ability was measured on the scale of 0 to 20 .

\section{Depression level}

The Short Form of Geriatric Depression Scale (SGDS) suggested by Gi (1996) was used to measure the depression of the subjects over the past week, and the form was composed of a total of 15 questions. The higher the score, the higher the depression level of the subjects. The Cronbach's $\alpha$ in this study was .88. Their depression level was self-measured.

\section{Analysis methods}

The non-parametric test was conducted to analyze changes before and after performing the horticultural therapy program using SPSS Win 19.0K. Changes in each factor before and after performing the program in the experimental group were analyzed using the Wilcoxon signed-rank test, and the significance level was $p<.05$.

\section{Results and Discussion}

\section{Changes in the word-recall ability}

To examine changes in the word-recall ability of the subjects before and after performing the program, the word-recall ability test was conducted, and the score increased from $8.6 \pm 1.2$ before the program to $9.4 \pm 0.6$ after the program, up by 0.8 points. Their statistical significance was tested using the Wilcoxon signed-rank test, and the results are as shown in Table 2. Out of a total of 13 subjects, 2 subjects were negatively ranked and 8 subjects were positively ranked. The rest 3 subjects were ranked the same, and the test results were found to be statistically significant ( $p=.012)$. As the results of an earlier study that topics and materials that induce recollection can further accelerate recollection and induce positive emotions (Lee et al., 2008), materials from nature that can stimulate recollection were provided in each session, and they were found to have a positive impact on the word-recall ability of the subjects in this study.

Horticultural activities make participants self-reflect through the growth process of plants, grow the patience of partici-

Table 2. Changes in word recall abilities before and after program implementation

\begin{tabular}{|c|c|c|c|c|c|c|c|}
\hline \multirow{2}{*}{ Division } & \multirow{2}{*}{ Frequency } & \multirow{2}{*}{ Mean rank } & \multirow{2}{*}{ Rank sum } & \multicolumn{2}{|c|}{$\mathrm{M} \pm \mathrm{SD}$} & \multirow{2}{*}{$\mathrm{z}$} & \multirow{2}{*}{$p$} \\
\hline & & & & Before & After & & \\
\hline Negative rank ${ }^{\mathrm{z}}$ & 2 & 1.5 & 3.0 & \multirow{4}{*}{$8.6 \pm 1.8$} & \multirow{4}{*}{$9.4 \pm 0.6$} & \multirow{4}{*}{-2.515} & \multirow{4}{*}{$.012^{*}$} \\
\hline Positive rank ${ }^{\mathrm{y}}$ & 8 & 6.5 & 52.0 & & & & \\
\hline Same $\operatorname{rank}^{\mathrm{x}}$ & 3 & & & & & & \\
\hline Total & 13 & & & & & & \\
\hline
\end{tabular}

${ }^{\mathrm{z}}$ word recall ability after program $<$ word recall ability before program

${ }^{\mathrm{y}}$ word recall ability after program $>$ word recall ability before program

${ }^{\mathrm{x}}$ word recall ability after program $=$ word recall ability before program

* Significant at $p<.05$ by wilcoxon signed-rank test. 
pants as they maintain plants, and continuously provide cognitive stimulations such as recalling the memory of the past (Lee and Seo, 2001). Horticultural therapy that uses this recollection technique was found effective in improving the cognitive function of patients with dementia (Cho, 2008), and the results also coincided with the results of another study that a horticultural therapy program using memory recalling materials improved the cognitive function of the elderly with dementia (Lee, 2012). In another study on the effects of singing on the word recollection of patients with early dementia (M.A. Kim, 2003), the number of words that the group of singing immediately recalled was higher than that the group of reading did, which supports the idea that singing familiar songs is effective in improving memory (Prickett and Moore, 1991).

One memory leads another memory (Park, 2007), and when participating in a group activity, one memory recalled by a person serves as a signal for recollection that evokes others' memory (Kim, 2010). In this study, group horticultural activities seemed to promote exchanges between people, and to be more effective.

\section{Changes in the level of depression}

To measure the level of depression before and after performing the program, the Short Form of Geriatric Depression Scale (SGDS) was used, and the average score decreased from $6.5 \pm 1.2$ before the program to $5.1 \pm 5.6$ after the program, down by 1.4 points. The Wilcoxon signed-rank test was performed and the results were as shown in Table 3. Out of a total of 13 subjects, 6 subjects were negatively ranked and 3 subjects were positively ranked. The rest 4 subjects were ranked the same, and there was no statistically significant difference $(p=.192)$.

Do (2007) reported that horticultural therapy improved the physical and mental health of the elderly and reduced lethargy, but, in another study, the horticultural therapy program using materials that stimulate recollection did not result in any statistically significant difference, although the depression level of the experimental group after participating in the program was lower than that of the control group (Lee, 2012). There was also no statistically significant difference in this study.

The results can be attributed to the findings that $40 \sim 50 \%$ of patients with dementia show symptoms of depression, particularly in the early stage of dementia (Gwon, 2010), and that neurotoxic homocysteine causes psychiatric problems such as depression symptoms (Hwang et al., 2014), which cannot be addressed in a short period of time. However, when people directly touch soil related to the survival of plants, Mycobacterium vaccae in soil is transmitted to the brain and activates the secretion of serotonin that gives a sense of happiness (Lowry et al., 2007), but homocysteine reduces the concentration of the antecedent precursors of neurotransmitters such as serotonin and dopamine (Hwang et al., 2014). In this study, activities of touching soil were included only in three sessions, but it will be necessary to continuously perform various horticultural activities using soil and plants in order to achieve therapeutic effects such as mental rehabilitation and

Table 3. Changes in geriatric depression scale before and after program implementation

\begin{tabular}{|c|c|c|c|c|c|c|c|}
\hline \multirow{2}{*}{ Division } & \multirow{2}{*}{ Frequency } & \multirow{2}{*}{ Mean rank } & \multirow{2}{*}{ Rank sum } & \multicolumn{2}{|c|}{$\mathrm{M} \pm \mathrm{SD}$} & \multirow{2}{*}{$\mathrm{z}$} & \multirow{2}{*}{$p$} \\
\hline & & & & Before & After & & \\
\hline Negative rank ${ }^{\mathrm{z}}$ & 6 & 5.6 & 33.5 & \multirow{4}{*}{$6.5 \pm 1.2$} & \multirow{4}{*}{$5.1 \pm 5.6$} & \multirow{4}{*}{-1.305} & \multirow{4}{*}{$.192^{\mathrm{NS}}$} \\
\hline Positive $\operatorname{rank}^{\mathrm{y}}$ & 3 & 3.8 & 11.5 & & & & \\
\hline Same $\operatorname{rank}^{\mathrm{x}}$ & 4 & & & & & & \\
\hline Total & 13 & & & & & & \\
\hline
\end{tabular}

${ }^{\mathrm{z}}$ word recall ability after program $<$ word recall ability before program

${ }^{\mathrm{y}}$ word recall ability after program $>$ word recall ability before program

${ }^{\mathrm{x}}$ word recall ability after program $=$ word recall ability before program

${ }^{\mathrm{NS}}$ Non-significant by wilcoxon signed-rank test. 
the reduction of the level of depression.

\section{Conclusion}

In this study, horticultural activities using horticultural materials that can recall memories were performed, and after that people sang songs. Changes in the word-recall ability and depression level of the elderly with mild dementia were measured. The word-recall ability of the subjects was assessed using 10 cards, and it was found that singing, training with materials that induce the recollection of the past, and performing horticultural activities by stage were helpful for the elderly with mild dementia to recollect input words. In addition, there was no significant difference in the score of depression after doing horticultural activities while talking about interesting stories that they experienced in the past, and singing after the activities. This shows that psychiatric problems cannot be easily addressed due to neurotoxic homocysteine caused by dementia. However, since the subjects looked forward to the program, and always actively participated in the program, it is difficult to conclude that the program was not effective in terms of the emotional aspect.

As earlier studies, as well as this study, showed that utilizing recollection in treating the elderly with dementia and memory disorder was effective in improving their cognitive and emotional functions (Oang, 2006; Cho, 2008), making the elderly with mild dementia often recall their long-term memory seems to be effective in relieving the symptoms of mild dementia. In order to induce physiological changes in the emotional function, it will be necessary to adopt a more scientific and systematic approach and thus to induce hormonal changes in the body through various horticultural activities.

\section{References}

Aldrige, D. 1994. Alzheimer's disease: Rhythm, timing and music as therapy. Biomed. Pharmacother. 48(7):275-281.

Bullock, R. and G. Hammond. 2003. Realistic expectations: The management of severe Alzheimer disease. Alzheimer Dis. Assoc. Disord. 17(Suppl 3):S80-85.

Butler, R.N. 1963. The life review: An interpretation of reminiscence in the aged. Psychiatry 26:65-76. DOI:10.1080/00332747.1963.11023339

Cho, M.G. 2008. Horticultural therapy as non-pharmacological treatment for the improvement of cognitive function and BPSD in dementia. Doctoral dissertation, Konkuk University, Seoul, Korea.

Clair, A.A. and B. Bernstein. 1990. A comparison of singing, vibrotactile and nonvibrotactile instrumental playing responses in severely regressed persons with dementia of the Alzheimer's type. J. Music Ther. 27(3):119-125.

DOI:10.1093/jmt/27.3.119

Davis, S. 1994. Ninth annual congressional initiatives award ceremonies. Washington, DC: Senate Rusell Office Building.

Do, R.J. 2007. Application and effect of the horticultural therapy program for life quality improvement on elderly peoples in the health-longevity rural community. Master's thesis, Seoul University, Seoul, Korea.

Gi, B.S. 1996. A preliminary study for the standardization of geriatric depression scale short form-Korea version. J. Korean Neuropsychiatr. Assoc. 35(2):298-307.

Gwon, J.D. 2010. Elderly welfare. Seoul, Korea: Hakjisa.

Hamachek, D. 1990. Evaluating self-concept and ego status in Erikson's last three psychosocial stages. J. Couns. Dev. 68(6):677-683. DOI:10.1002/j.1556-6676.1990.tb01436.x

Han, T.J. 2010. Plants and medicare. Seoul, Korea: Book publishing Sowha.

Heo, B.G. and Y.J. Park. 2010. Horticultural therapy guide learn from movies. Seoul, Korea: Joongang Life Publishing Co.

Hwang, B.R., H. Kim, and K.J. Lee. 2014. The differences of serum homocysteine levels in mild cognitive impairment and dementia of Alzheimer's type with or without depressive symptoms. Korean J. Psychosom. Med. 22(1):40-45. 
Jung, H.J. 2006. Music therapy techniques and models. Seoul, Korea: Hakjisa.

Jung, K.A. 2008. Dietary nutrition status and cognitive function of cognitive impairment in the elderly. Master's thesis, Ewha Womans University, Seoul, Korea.

Keightley, J. and A. Mitchell. 2004. What factors influence mental health professionals when deciding whether or not to share a diagnosis of dementia with the person? Aging Ment. Health 8(1):13-20.

Kim, H.N. and W.K. Park. 2015. The effect of horticultural activities program on depression of the dementia elderly at the facility. J. Korean Aging Friendly Ind. Assoc. 7(2):13-20.

Kim, H.Y. 2003. Theory and practice of horticultural therapy. Daegu, Korea: Korean horticultural therapy research center.

Kim, M.A. 2003. The effect of singing on word recall of moderately demented patients. Korean J. Music Ther. 5(1):71-82.

Kim, M.L, 2010. Effects of horticultural therapy program with reminiscence on the elderly with chronic diseases focusing on ego integrity and self-esteem. Master's thesis, Uiduk University, Gyeongju, Korea.

Kong, J.H., S.Y. Yun, and B.J. Choi. 2015. The effects of reminiscence- based horticultural therapy on institutionalized demented elders' self-esteem and quality of life. J. Korean Soc. People Plants Environ. 18(4):305-309.

Lee, E.S., M.K. Cho, J.W. Choi, and K.C. Son. 2008. Effect of horticultural therapy program based on reminiscence on the psychological and physiological improvement of the aged. Korean J. Hortic. Sci. Technol. 26(2):177-188.

Lee, H.J. 2012. Effects of the horticultural therapy program using reminiscence stimulation materials on cognition and depression of the elderly with dementia. Master's thesis, Dankook University, Cheonan, Korea.

Lee, S.M. and J.K. Seo. 2001. Aging society and the role of hoticultural therapist-Focused on loss of the role of the elderly-. J. Korean Soc. People Plants Environ. 4(2):21-29.

Lord, T.R. and J.E. Garner. 1993. Effects of music on Alzheimer's patients. Percept. Mot. Skills 76(2):451-455.

Lowry, C.A., J.H. Hollis, A. de Vries, B. Pan, L.R. Brunet, J.R.F. Hunt, J.F.R. Paton, E. van Kampen, D.M. Knight, A.K. Evans, G.A.W. Rook, and S.L. Lightman. 2007. Identification of an immune-responsive mesolimbocortical serotonergic system: potential role in regulation of emotional behavior. Neuroscience 146:(2-5):756-772.

DOI:10.1016/j.neuroscience.2007.01.067

Oang, G.S. 2006. Effects of horticultural therapy on elderly people's self-integration. Master's thesis, Pusan National University, Pusan, Korea.

Park, K.A. 2007. A study on the effectiveness of group reminiscence program on the depression and cognitive ability of patients with severe dementia; the case of patients in geriatric hospital. Master's thesis, Ewha Womans University, Seoul, Korea.

Prickett, C.A. and R.S. Moore. 1991. The use music to aid memory of Alzheimer's patients. J. Music Ther. 28(2):101-110. DOI:10.1093/jmt/28.2.101

Radocy, E.R. and Boyle, J.D. 1988. Psychological foundations of musical behavior(2nd ed.) Springfield, IL: Charles C Thomas Pub. 